\title{
MTHFR polymorphisms in gastric cancer and in first-degree relatives of patients with gastric cancer
}

\author{
Valli De Re $\cdot$ R. Cannizzaro $\cdot$ V. Canzonieri • \\ E. Cecchin $\cdot$ L. Caggiari $\cdot$ E. De Mattia $\cdot$ C. Pratesi • \\ P. De Paoli • G. Toffoli
}

Received: 21 July 2009 /Accepted: 4 November 2009/Published online: 18 December 2009

(C) The Author(s) 2009. This article is published with open access at Springerlink.com

\begin{abstract}
Two common mutations, $677 \mathrm{C} \rightarrow \mathrm{T}$ and a1298 $\mathrm{A} \rightarrow \mathrm{C}$, in the methylenetetrahydrofolate reductase gene (MTHFR) reduce the activity of MTHFR and folate metabolism. Familial aggregation in a variable but significant proportion of gastric cancer (GC) cases suggests the importance of genetic predisposition in determining risk. In this study, we evaluate MTHFR polymorphisms in 57 patients with a diagnosis of GC, in 37 with a history of GC in first-degree relatives (GC-relatives), and in 454 blood donors. Helicobacter pylori (HP) infection was also determined. An increased risk was found for 677TT in GC patients with respect to blood donors (odds ratio $(\mathrm{OR})=1.98$ ), and statistical significance
\end{abstract}

V. De Re $\cdot$ E. Cecchin $\cdot$ L. Caggiari $\cdot$ E. De Mattia $\cdot$ G. Toffoli Experimental and Clinical Pharmacology, Centro di Riferimento Oncologico, IRCCS, National Cancer Institute,

Aviano, Italy

R. Cannizzaro

Gastroenterology, Centro di Riferimento Oncologico, IRCCS, National Cancer Institute,

Aviano, Italy

V. Canzonieri

Pathology, Centro di Riferimento Oncologico, IRCCS,

National Cancer Institute,

Aviano, Italy

C. Pratesi $\cdot$ P. De Paoli

Microbiology, Centro di Riferimento Oncologico, IRCCS,

National Cancer Institute,

Aviano, Italy

V. De Re $(\bowtie)$

Farmacologia Sperimentale e Clinica, DOMERT,

Dipartimento di Oncologia Molecolare e Ricerca Traslazionale,

Centro di Riferimento Oncologico, IRCCS,

Via Franco Gallini 2,

33081 Aviano, Pordenone, Italy

e-mail: vdere@cro.it was sustained when we compared sex-age-matched GC patients and donors $(\mathrm{OR}=2.37)$. The 677TT genotype association with $\mathrm{GC}$ was found in women $(\mathrm{OR}=3.10)$, while a reduction in the $667 \mathrm{C}$ allele frequency was present in both the sex. No statistically significant association was detected when 677-1298 genotype was stratified by sex and age. Men of GC-relatives showed a higher 1298C allele frequency than donors $(\mathrm{OR}=4.38)$. Between $\mathrm{GC}$ and $\mathrm{GC}$-relatives, $\mathrm{HP}$ infection frequency was similar. In conclusion, overall findings support the hypothesis that folate plays a role in GC risk. GC-relatives evidence a similar 677TT frequency to that found in the general population.

Keywords Methylenetetrahydrofolate reductase (MTHFR) polymorphism · Gastric carcinoma - Gastric cancer familiarity $\cdot$ Helicobacter pylori

\section{Introduction}

Although the incidence of gastric cancer (GC) decreases worldwide, at present, it is still the fourth more frequent tumor in the world [1]. There are however major geographical differences among different countries. Regions with a high incidence include East Asia (China and Japan), Eastern Europe, and parts of Central and South America. Areas with a low incidence include Southern Asia, North and East Africa, and North America [2]. Within the European Union, the highest incidence rate is in Lithuania; the lowest is in Denmark. In Italy, GC incidence of female and male is 27.7 and 40.7 cases every 100,000 habitants, respectively [3]. GC is usually diagnosed at an advanced stage, with $>50 \%$ of patients having stage 3 or 4 disease at presentation. Advanced GC has a poor prognosis, with a relative 5-year survival rate of $7-27 \%$ [4]. 
It is generally accepted that multiple factors play a role in GC development, including diet, lifestyle, infectious agents such as Helicobacter pylori, and genetic factors as well as gene-environment interactions [2]. Although the continuous decrease in the incidence of GC [5] in recent decades can be explained by changing lifestyle, diet habits, and reduced $H$. pylori infection, the fact that some individuals develop GC while others do not under similar environmental exposures suggests that genetic predisposition plays an important role in the pathogenesis of this disease. Approximately 10-15\% of gastric cancers arise in individuals with a family history of the condition, while the risk of GC increases in first-degree relatives of patients with the disease by approximately twoto threefold [6-8]. This may be partially due to the fact that relatives tend to be exposed to the same environmental risk factors, but also to inheritable susceptibility. In addition, a more common coincidence of the disease in homozygotic than in heterozygotic twins [9] also supports genetic links with GC. Only a few studies have investigated the association of family history with GC. No significant associations emerged to sex or age, education, body mass index, or tobacco smoking, while the odds ratio (OR) was higher when the affected relative was a sibling rather than a parent [10,11]. Lifestyle and diet may explain this finding, since it is possible that patients shared lifestyle more with sibling than with parents. Although the H. pylori infection, the best-established risk factor for $\mathrm{GC}$, tends to be more frequently found among family members [12-14], it is still controversial if the risk for $\mathrm{GC}$ is associated with $H$. pylori status in these patients.

Methylenetetrahydrofolate reductase (MTHFR) is a key enzyme in the metabolism of folate, whose role in GC, though not always consistent in various studies [15], has been supported by several meta-analyses [16-19]. Folate deficiency may cause uracil misincorporation and subsequent DNA instability [20], retarded DNA repair capacity for oxidative or alkylating damage [21], and favor global and oncogenic DNA hypomethylation [22]; all effects that can be involved in carcinogenesis, including the GC [23,24]. Folate is one of the important constituents in fruit and vegetables, and epidemiologic studies have shown that a small consumption of vegetables and fruits is associated with increased risk of GC [25-27]. In most studies, the 677TT variant genotype was associated with an increased risk of GC [16-19]. Accordingly, individuals who are homozygous for this variant have $30 \%$ of the expected "in vitro" enzyme activity compared with those who are homozygous for the CC677, whereas heterozygous carriers have a $65 \%$ enzyme activity [28]. Patients with the second variant $1298 \mathrm{CC}$ have a less essential reduced folate reductase activity of $60 \%$ compared with subjects carrying the AA1298 wild-type genotype, and $80 \%$ for the heterozygotes. The $1298 \mathrm{CC}$ was generally not associated with $\mathrm{GC}$ risk in Caucasian population, while the same was found to be a controversial risk factor mainly in East Asia [16,17]. In animal models, an intervention study provided evidence on the chemopreventive effect of folic acid on GC [29]; while epidemiological studies on humans were not so conclusive. Evidence for a significant association between dietary folate intake and risk of GC was inconsistent in some studies [15,18], and supported in others [17,19].

The present study tries to give an insight in the role of MTHFR polymorphism in the northeast Italian GC population, and with respect to family history. To our knowledge, this is the first study aiming at examining the frequency of MTHFR genetic variations in association with a risk population from first-degree GC family history.

\section{Material and methods}

\section{Study population}

Baseline characteristics of the study population were reported in Table 1. Fifty-seven unrelated patients, with a histologically confirmed GC (35 male and 22 female) age 37 years or more, were recruited into the study. All patients had a Caucasian ethnic background and were resident in northeast Italy. They underwent clinical examination at the Centro di Riferimento Oncologico (Aviano, Italy) between 2003 and 2008. Their median age was 54.

Between 2004 and 2008, 37 individuals (21 male and 16 female), who reported an ascertained case of GC among firstdegree relatives (parents, children, siblings, and offsprings), were consecutively recruited from the same center. Their median age was 44 years. Fifteen familiar histories with more than one individual participating in the study were illustrated in Fig. 1, remaining GC cases were not illustrated since represented by only one family member. All subjects enrolled were volunteers. Neither cancer nor intestinal metaplasia/dysplasia was evidenced in these subjects by gastroscopy and histological examination.

The control group comprised 454 blood donors younger than 66 years (311 male and 143 female), recruited from the same center. Their median age was 40 years. The advanced age of patients with GC (mean 54 years; minimum 37; maximum 84) reduced the number of recruited controls useful for the case-control analysis. Each matched case-control included one case and two controls, then, ninety-six donors were matched in sex and age ( \pm 1 year) to 48 individuals with GC.

Blood sample collection and DNA extraction

A venous blood sample was drawn from each of the participants. Our institution's review board has approved the study proposal according to the Declaration of Helsinki, and a written informed consent was obtained from subjects. 
Table 1 Baseline characteristics of the study population

\begin{tabular}{llc}
\hline & Numbers & Mean of age at diagnosis/selection (minimum-maximum) \\
\hline Controls & 454 & $40(18-66)$ \\
Sex- and age-matched controls & 96 & $49(37-64)$ \\
Men & $315(68.50 \%)$ & $40(19-65)$ \\
Women & $139(31.50 \%)$ & $38(18-66)$ \\
$<54$ years & $411(90.53 \%)$ & $36(18-53)$ \\
$\geq 54$ years & $43(09.47 \%)$ & $58(54-66)$ \\
GC cases & 57 & $54(37-84)$ \\
Sex- and age-matched GC & 48 & $48(37-64)$ \\
Men & $35(61.40 \%)$ & $55(39-84)$ \\
Women & $22(38.60 \%)$ & $52(37-75)$ \\
$<54$ years & $29(50.88 \%)$ & $46(37-53)$ \\
$\geq 54$ years & $28(49.12 \%)$ & $62(54-84)$ \\
GC-relatives cases & 37 & $44(25-74)$ \\
Men & $21(56.76 \%)$ & $47(25-74)$ \\
Women & $16(43.24 \%)$ & $41(31-60)$ \\
$<54$ years & $29(78.38 \%)$ & $39(25-49)$ \\
$\geq 54$ years & $8(21.62 \%)$ & $64(57-74)$ \\
\hline
\end{tabular}

Genomic DNA was extracted using the QiaAmp DNA Mini Kit (Qiagen, Valencia, California, USA). Genomic DNA in solution was stored at $4^{\circ} \mathrm{C}$.

\section{MTHFR genotyping}

Predesigned Taq Man ${ }^{\circledR}$ SNP genotyping assays were used on ABI 7900HT (AB Applied Biosystems, Foster City, CA) according to the manufacturer's instructions for the discrimination of the $677 \mathrm{C} \rightarrow \mathrm{T}$ (rs1801133) and $1298 \mathrm{~A} \rightarrow \mathrm{C}$ (rs1801131) polymorphisms. The Applera TaqMan Universal Master ${ }^{\circledR}$ mix was employed together with the validated primers and probes mix at the usage concentration as provided by the manufacturer. Positive controls were included in the analyses.

\section{H. pylori identification}

Routine formalin-fixed and paraffin wax-embedded pairs of antrum, corpus, and fundus biopsies from GC patients and GC-relatives were investigated by histology. Sections were stained with hematoxylin and eosin (H\&E) and examined under light microscope at $\times 40$ magnifications. Bouin's solution is an excellent fixative for the identification of $H$. pylori (HP) in H\&E-stained sections.

\section{Statistical analyses}

Hardy-Weinberg equilibrium was assessed by $\chi^{2}$ analysis. For each groups, subjects were divided according to MTHFR genotype. The odds ratio and 95\% confidence interval $(95 \% \mathrm{CI})$ were calculated to estimate the relative risk of GC associated with MTHFR genotype [30]. GraphPad software (Inc, San Diego, CA) was used to perform Fisher's exact test to compare two categorical variables.

\section{Results}

We analyzed 677 and 1,298 variants in a series of 454 blood donors, $57 \mathrm{GC}$, and 37 GC-relatives recruited at the same center; all were of a Caucasian ethnic background and resident in northeast Italy. Among blood donors, two consecutive sexand age-matched individuals every one case of GC were selected ( $n=96$ matched controls for $48 \mathrm{GC}$ ). The description of the study populations and of the observed MTHFR polymorphisms was reported in Tables 1, 2, and 3, respectively. In patients with $\mathrm{GC}$, distribution of 677TT genotype showed a significant difference from controls $(24.56 \%$ vs $14.10 \%, \mathrm{OR}=1.98,95 \% \mathrm{CI}: 1.037$ to 3.833$)$, while they did not statistically differ in the $1298 \mathrm{CC}$ (Tables 2 and 3). The unfavorable 677TT variant showed also an increased frequency in GC samples $(27.08 \%)$ with respect to age- and sex-matched controls $(13.54 \%, \mathrm{OR}=2.37$; $95 \% \mathrm{CI}$ : 0.999 to 5.628; Tables 2 and 3). The difference is associated with a higher homozygous 677TT variant in women (OR= 3.10; $95 \% \mathrm{CI}$ : 1.052 to 9.135 , Table 2) to compared with women control group, and with a lower $667 \mathrm{C}$ wild-type allele frequency in GC of both sex with respect to controls (Table 3). Table 4 details the distribution of $677-1298$ genotype polymorphisms and sex and age. Odd ratio analysis was obtained by comparison with a reference group of 

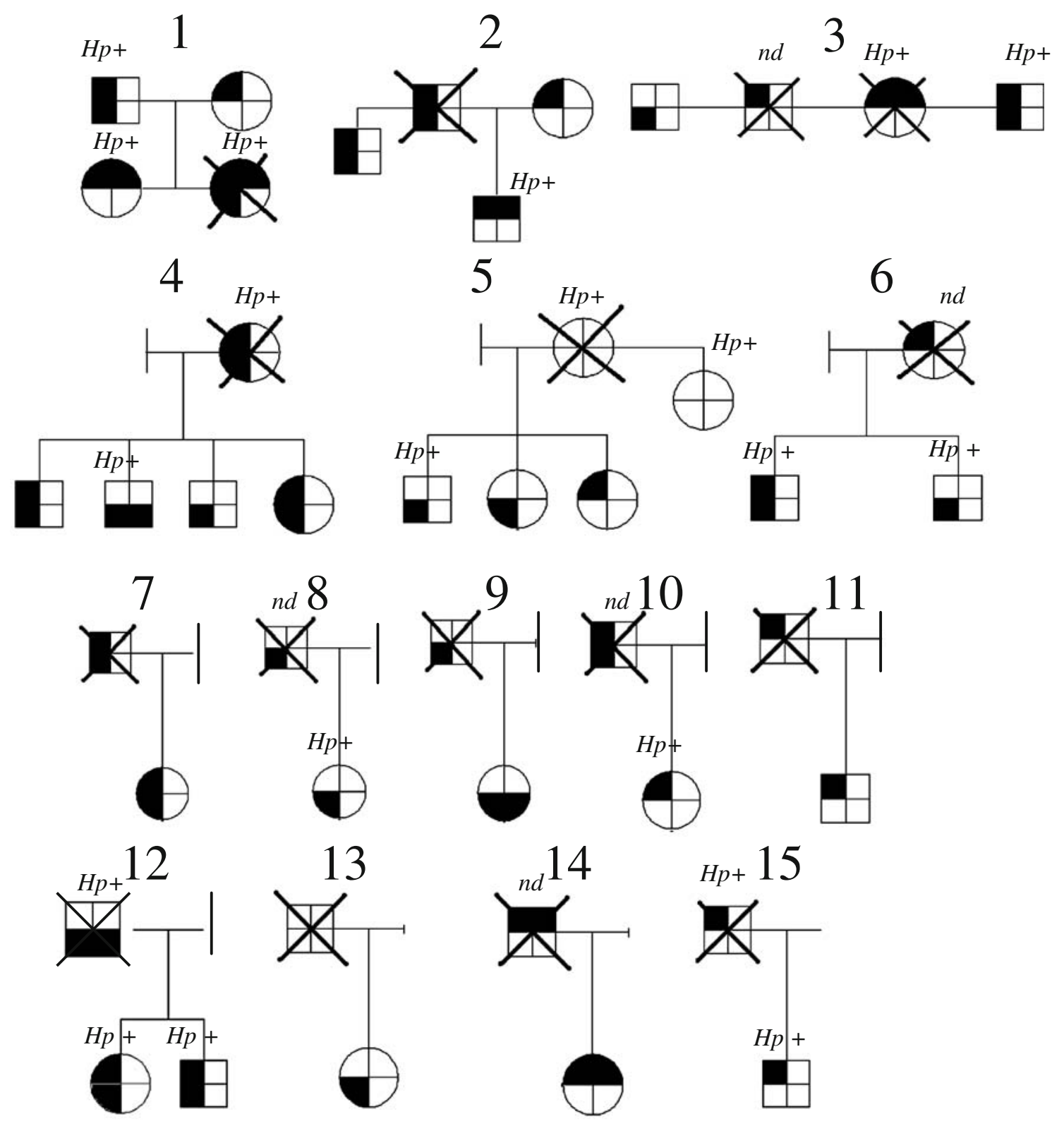

Pedigree's symbols
$=$ heterozyote for $677 \mathrm{~T}$ mutation; monozygote for $677 \mathrm{~T}$ mutation
Omissis data: negative histological Helicobacter Pylori identification;
nd: Helicobacter Pylori was not tested


Fig. 1 The 677 and 1298 genotypes analysis and H. pylori infection status of 15 pedigrees with at least one first-degree GC-affected member. Figure illustrates 15 representative family histories with at least one subject with a histological ascertained GC. Only subjects in first-degree GC-relatives were included in the GC-family group for the study. Ten cases were excluded from the figure, because the biopsies from their first-degree GC relatives were not available

individuals carrying the two wild-type 677CC and 1298AA alleles. Data for men showed a trend to an increased frequency of both MTHFR 677 and 1298 variant genotypes in GC cases, while women showed a possible GC risk reduction associated with the homozygous variant MTHFR 1298CC genotype. The association of MTHFR variant association also seems to be influenced by the age of patients (age $\geq 54$ ). However, none of the above reported differences reach any statistical significance in our series.

Any samples showed genotype in homozygosis for both the 677TT and 1298CC polymorphisms. By converse, GCrelatives showed a similar 677TT genotype frequency (13.5\%) than control samples (14.1\%); not even a statistically significant difference in $1298 \mathrm{CC}$ genotype frequencies was found between the GC-relatives and controls (Tables 2 and 3). An increase in 1298 heterozygosis was found in GC- relatives with respect to GC (Table 2). Stratification of 677 1298 genotypes by sex and age was similar to that found in GC cases to compare with donors; and also in this situation, data did not reach any statistical significance (Table 5).

In Fig. 1, the 677 and 1298 allele distribution was illustrated in 15 families with more than one subject enrolled in the study for a total of 27 GC-relatives. Additional ten GC-relatives, as single case, were not shown in Fig. 1. Neither cancer nor intestinal metaplasia/dysplasia was evidenced in these individuals by gastroscopy and histological examination. Data from histological identification of $H$. pylori were reported across family group in Fig. 1. HP infection was frequently found within related subjects. Hp infection frequencies in GC and GC-relative groups and their relative distribution in 677 genotypes were resumed in Fig. 2. There was no statistically significant difference in Hp distribution among all the groups tested.

\section{Discussion}

The high mortality of GC is largely attributed to the huge number of at-risk individuals as well as to the delay in

Table 2 Genotypic of the MTHFR 667 and 1298 polymorphisms in controls, GC patients, and GC-first grade relatives

\begin{tabular}{|c|c|c|c|c|c|c|c|}
\hline & \multirow[t]{2}{*}{ Numbers } & \multicolumn{3}{|l|}{667 genotype } & \multicolumn{3}{|c|}{1298 genotype } \\
\hline & & $\mathrm{CC}$ & $\mathrm{CT}$ & $\mathrm{TT}$ & AA & $\mathrm{AC}$ & $\mathrm{CC}$ \\
\hline Controls & 454 & $152(33.5 \%)$ & $238(52.4 \%)$ & $64(14.1 \%)$ & $179(39.4 \%)$ & $234(51.5 \%)$ & $41(9.0 \%)$ \\
\hline Sex- and age-matched controls & 96 & $37(38.6 \%)$ & $46(47.9 \%)$ & $13(13.5 \%)$ & $33(34.4 \%)$ & $54(56.2 \%)$ & $9(9.4 \%)$ \\
\hline Men & 315 & 100 & 166 & 49 & 133 & 158 & 24 \\
\hline Women & 139 & 52 & 72 & 15 & 46 & 76 & 17 \\
\hline$<54$ years & 411 & 139 & 215 & 57 & 161 & 211 & 39 \\
\hline$\geq 54$ years & 43 & 13 & 23 & 7 & 18 & 23 & 2 \\
\hline GC cases & 57 & $18(31.6 \%)$ & $25(43.9 \%)$ & $14(24.6 \%)^{\mathrm{a}}$ & $25(43.9 \%)$ & $27(47.4 \%)$ & $5(8.8 \%)$ \\
\hline Sex- and age-matched GC & 48 & $12(25.0 \%)$ & $23(47.9 \%)$ & $13(27.1 \%)^{b}$ & $24(50.0 \%)$ & $19(39.6 \%)$ & $5(10.4 \%)$ \\
\hline men & 35 & 10 & 17 & 8 & 13 & 18 & 4 \\
\hline women & 22 & 8 & 8 & $6^{\mathrm{c}}$ & 12 & 9 & 1 \\
\hline$<54$ years & 29 & 7 & 16 & 6 & 15 & 11 & 3 \\
\hline$\geq 54$ years & 28 & 11 & 9 & 8 & 10 & 16 & 2 \\
\hline GC-relatives cases & 37 & $14(37.8 \%)$ & $18(48.6 \%)$ & $5(13.5 \%)$ & $9(25.7 \%)$ & $26(70.3 \%)^{\mathrm{d}}$ & $2(5.7 \%)$ \\
\hline Men & 21 & 8 & 11 & 2 & $3^{\mathrm{e}}$ & $17^{\mathrm{f}}$ & 1 \\
\hline Women & 16 & 6 & 7 & 3 & 6 & 9 & 1 \\
\hline$<54$ years & 29 & 12 & 13 & 4 & 7 & 20 & 2 \\
\hline$\geq 54$ years & 8 & 2 & 5 & 1 & 2 & 6 & 0 \\
\hline
\end{tabular}

${ }^{\mathrm{a}} \mathrm{OR}=1.98,95 \% \mathrm{CI}: 1.027$ to 3.833 , with respect to controls

${ }^{\mathrm{b}} \mathrm{OR}=2.37,95 \% \mathrm{CI}: 0.999$ to 5.628 , with respect to sex- and age-matched controls

${ }^{\mathrm{c}} \mathrm{OR}=3.10,95 \% \mathrm{CI}: 1.052$ to 9.135 , with respect to women controls

${ }^{\mathrm{d}} \mathrm{OR}=2.22,95 \% \mathrm{CI}: 1.072$ to 4.605 , with respect to controls

${ }^{\mathrm{e}} \mathrm{OR}=0.23,95 \% \mathrm{CI}: 0.066$ to 0.790 , with respect to men controls

${ }^{\mathrm{f}} \mathrm{OR}=4.22,95 \% \mathrm{CI}: 1.389$ to 12.84 , with respect to men controls 
Table 3 Allele frequencies of the MTHFR 667 and 1298 polymorphisms in controls, GC patients, and GC-first grade relatives

\begin{tabular}{|c|c|c|c|c|c|}
\hline & \multirow[t]{2}{*}{ Numbers } & \multicolumn{2}{|c|}{667 allele frequency } & \multicolumn{2}{|c|}{1298 allele frequency } \\
\hline & & $\mathrm{C}$ & $\mathrm{T}$ & A & $\mathrm{C}$ \\
\hline Controls & 454 & $390(85.9 \%)$ & $302(66.5 \%)$ & $413(90.1 \%)$ & $275(60.6 \%)$ \\
\hline Sex- and age-matched controls & 96 & $83(86.5 \%)$ & $59(61.5 \%)$ & $87(90.6 \%)$ & $63(65.6 \%)$ \\
\hline Men & 315 & 266 & 215 & 291 & 182 \\
\hline Women & 139 & 124 & 87 & 122 & 93 \\
\hline$<54$ years & 411 & 354 & 272 & 372 & 250 \\
\hline$\geq 54$ years & 43 & 36 & 30 & 41 & 25 \\
\hline GC cases & 57 & $43^{\mathrm{a}}(75.4 \%)$ & $39(68.4 \%)$ & $52(91.2 \%)$ & $32(56.1 \%)$ \\
\hline Sex- and age-matched GC & 48 & $35(72.9 \%)$ & $36(75.0 \%)$ & $43(89.6 \%)$ & $24(50.0 \%)$ \\
\hline Men & 35 & $27^{\mathrm{b}}$ & 25 & 31 & 22 \\
\hline Women & 22 & $16^{\mathrm{c}}$ & 14 & 21 & 10 \\
\hline$<54$ years & 29 & 22 & 21 & 26 & 13 \\
\hline$\geq 54$ years & 28 & 21 & 18 & 26 & 19 \\
\hline GC-relatives cases & 37 & $32(86.5 \%)$ & $23(62.2 \%)$ & $35(94.6 \%)$ & $28(75.7 \%)$ \\
\hline Men & 21 & 19 & 13 & 20 & $18^{\mathrm{d}}$ \\
\hline Women & 16 & 13 & 10 & 15 & 10 \\
\hline$<54$ years & 29 & 25 & 17 & 27 & 22 \\
\hline$\geq 54$ years & 8 & 7 & 6 & 8 & 6 \\
\hline
\end{tabular}

${ }^{\mathrm{a}} \mathrm{OR}=0.50,95 \% \mathrm{CI}: 0.261$ to 0.974 , with respect to controls

${ }^{\mathrm{b}} \mathrm{OR}=0.41,95 \% \mathrm{CI}: 0.197$ to 0.875 , with respect to men controls

${ }^{\mathrm{c}} \mathrm{OR}=0.32$, $95 \% \mathrm{CI}: 0.109$ to 0.950 , with respect to women controls

${ }^{\mathrm{d}} \mathrm{OR}=4.385,95 \% \mathrm{CI}: 1.265$ to 15.195 , with respect to men controls

presentation. Hence, the prevention and an early identification of GC seem to be the most promising approaches in reducing the incidence and mortality related to this cancer.

Some possible risk factors that can be avoided in GCrelatives, i.e, smoking, alcohol consumption, dietary intake, H. pylori infection, have widely been studied with the aim of preventing GC. The risk of GC in family history was found to be independent of tobacco smoking [10]. Large alcohol consumption has been proved to contribute to GC, to reduce folate intestinal absorption, and to increase folate renal excretion [31,32]. According to a recent report from the World Cancer Research Fund and the American Institute for Cancer Research, there is a "probable evidence" that large consumption of nonstarchy vegetables and fruits might decrease the risk of GC, while salt and salted food might be directly associated with risk. For what regards the H. pylori infection, results from several largescale prospective randomized studies showed marginal benefits of $H$. pylori eradication on regression of premalignant gastric lesions while its importance is doubtful in the reduction of GC incidence [33]. However, since H. pylori eradication was demonstrated to prevent the recurrence of peptic ulcer and gastric cancer (secondary prophylaxis) and is the treatment of choice for patients with low grade gastric
MALToma [33], a substantial portion of GC-relatives could benefit from its eradication.

MTHFR is a key enzyme in the metabolism of folate which provides methyl donor for DNA synthesis and gene regulation [22]. Several studies have found an association between 677TT status and several risk of cardiovascular diseases [1] or cancers, as postmenopausal breast cancer [34], colorectal cancer [23,35,36], and lung cancer [37]. Recently, the association of 677TT and 1298CC polymorphisms and the risk of $\mathrm{GC}$ have been re-evaluated in four meta-analyses [16-19]. However, the effect of differential magnitude in different geographical regions was significant. MTHFR 677TT genotype was found to be a strong risk factor in Chinese and East Asian populations [16,17], a risk factor in some, but not in all populations in Italy $[15,16]$, Southern Europe [18,38,39], and in South America population studies $[18,19]$. It was found to be insignificant in other populations, as in the Korean or the North American ones [16,18]. GC association with $1298 \mathrm{CC}$ variant was limited to East Asian [16], and in a study on Southern Europe [15], while it resulted inconsistent in other studied populations $[18,19]$.

According to the majority of reports $[18,19,38]$, our data support the association between 677TT genotype and GC in Italy (OR $1.98495 \%$ CI: 1.027 to 3.8329 ), and this is 
Table 4 Association between MTHFR genotype and gastric cancer risk stratified by sex and age

\begin{tabular}{|c|c|c|c|c|c|c|c|c|c|c|c|c|}
\hline \multirow[t]{2}{*}{ MTHFR 677} & \multicolumn{4}{|l|}{ AA } & \multicolumn{4}{|c|}{ MTHFR 1298 AC } & \multicolumn{4}{|l|}{$\mathrm{CC}$} \\
\hline & $\begin{array}{l}\text { Cases } \\
(n)\end{array}$ & $\begin{array}{l}\text { Controls } \\
(n)\end{array}$ & OR & $95 \% \mathrm{CI}$ & $\begin{array}{l}\text { Cases } \\
(n)\end{array}$ & $\begin{array}{l}\text { Controls } \\
(n)\end{array}$ & OR & $95 \% \mathrm{CI}$ & $\begin{array}{l}\text { Cases } \\
(n)\end{array}$ & $\begin{array}{l}\text { Controls } \\
(n)\end{array}$ & OR & $95 \% \mathrm{CI}$ \\
\hline \multicolumn{13}{|c|}{ Overall GC cases } \\
\hline $\mathrm{CC}$ & 3 & 24 & 1.0 & - & 11 & 90 & 1.0 & $(0.3-3.8)$ & 4 & 38 & 0.8 & $(0.2-4.1)$ \\
\hline $\mathrm{CT}$ & 9 & 98 & 0.7 & $(0.2-2.9)$ & 15 & 137 & 0.9 & $(0.2-3.3)$ & 1 & 3 & 2.7 & $(0.2-34.5)$ \\
\hline $\mathrm{TT}$ & 13 & 57 & 1.8 & $(0.5-7.0)$ & 1 & 7 & 1.1 & $(0.1-12.8)$ & - & - & & \\
\hline \multicolumn{13}{|l|}{ Men } \\
\hline $\mathrm{CC}$ & 2 & 19 & 1.0 & - & 5 & 58 & 0.8 & $(0.1-4.6)$ & 3 & 23 & 1.2 & $(0.2-8.2)$ \\
\hline $\mathrm{CT}$ & 4 & 70 & 0.5 & $(0.1-3.2)$ & 12 & 95 & 1.2 & $(0.2-5.8)$ & 1 & 1 & 9.5 & $(0.4-217)$ \\
\hline $\mathrm{TT}$ & 7 & 44 & 1.5 & $(0.3-8.0)$ & 1 & 5 & 1.9 & $(0.1-25.0)$ & - & - & & \\
\hline \multicolumn{13}{|l|}{ Women } \\
\hline $\mathrm{CC}$ & 1 & 5 & 1.0 & - & 6 & 32 & 0.9 & $(0.1-9.5)$ & 1 & 15 & 0.3 & $(0.1-6.4)$ \\
\hline $\mathrm{CT}$ & 5 & 28 & 0.9 & $(0.1-9.3)$ & 3 & 42 & 0.3 & $(0.1-4.1)$ & - & 2 & 0.7 & $(0.1-25)$ \\
\hline TT & 6 & 13 & 2.3 & $(0.2-24.0)$ & 0 & 2 & 0.7 & $(0.1-25.0)$ & - & - & & \\
\hline \multicolumn{13}{|c|}{$\begin{array}{l}\text { Overall at the age of } \\
\text { diagnosis/selection } \\
<54 \text { years }{ }^{\mathrm{a}}\end{array}$} \\
\hline $\mathrm{CC}$ & 3 & 21 & 1.0 & - & 2 & 82 & 0.2 & $(0.0-1.1)$ & 2 & 36 & 0.4 & $(0.1-2.5)$ \\
\hline $\mathrm{CT}$ & 7 & 90 & 0.5 & $(0.1-2.3)$ & 8 & 122 & 0.5 & $(0.1-1.9)$ & 1 & 3 & 2.3 & $(0.2-30.4)$ \\
\hline $\mathrm{TT}$ & 5 & 50 & 0.7 & $(0.1-3.2)$ & 1 & 7 & 1.0 & $(0.1-11.2)$ & - & - & & \\
\hline \multicolumn{13}{|c|}{$\begin{array}{l}\text { Overall at the age of } \\
\text { diagnosis/selection } \\
\geq 54 \text { years }\end{array}$} \\
\hline $\mathrm{CC}$ & - & 3 & 1.0 & - & 9 & 8 & 7.8 & $(0.3-174)$ & 2 & 2 & 7.0 & $(0.2-219)$ \\
\hline $\mathrm{CT}$ & 2 & 8 & 2.1 & $(0.1-54.9)$ & 7 & 15 & 3.4 & $(0.1-74)$ & - & - & & \\
\hline $\mathrm{TT}$ & 8 & 7 & 7.9 & $(0.4-180)$ & - & - & & & - & - & & \\
\hline \multicolumn{13}{|c|}{$\begin{array}{l}\text { Men at the age of } \\
\text { diagnosis/selection } \\
<54 \text { years }\end{array}$} \\
\hline $\mathrm{CC}$ & 2 & 16 & 1.0 & - & - & 54 & 0.1 & $(0.0-1.3)$ & 1 & 21 & 0.4 & $(0.1-4.6)$ \\
\hline $\mathrm{CT}$ & 3 & 64 & 0.4 & $(0.1-2.4)$ & 6 & 83 & 0.6 & $(0.1-3.1)$ & - & 1 & & \\
\hline TT & 1 & 38 & 0.2 & $(0.1-2.5)$ & - & 5 & 0.6 & $(0.0-14)$ & - & - & & \\
\hline \multicolumn{13}{|c|}{$\begin{array}{l}\text { Men at the age of } \\
\text { diagnosis/selection } \\
\geq 54 \text { years }\end{array}$} \\
\hline $\mathrm{CC}$ & - & 3 & 1.0 & - & 5 & 4 & 8.5 & $(0.3-213)$ & 2 & 2 & 7 & $(0.3-219)$ \\
\hline $\mathrm{CT}$ & 1 & 6 & 1.6 & $(0.1-51.1)$ & 6 & 12 & 3.6 & $(0.2-81)$ & 1 & - & & \\
\hline $\mathrm{TT}$ & 6 & 6 & 7 & $(0.3-164)$ & 1 & - & & & - & - & & \\
\hline \multicolumn{13}{|c|}{$\begin{array}{l}\text { Women at the age of } \\
\text { diagnosis/selection } \\
<54 \text { years }\end{array}$} \\
\hline $\mathrm{CC}$ & 1 & 5 & 1.0 & - & 2 & 28 & 0.4 & $(0.1-4.7)$ & 1 & 15 & 0.3 & $(0.1-6.4)$ \\
\hline $\mathrm{CT}$ & 4 & 26 & 0.8 & $(0.1-8.4)$ & 2 & 39 & 0.3 & $(0.1-3.3)$ & - & 2 & & \\
\hline $\mathrm{TT}$ & 4 & 12 & 1.7 & $(0.2-18.9)$ & - & 2 & & & - & - & & \\
\hline \multicolumn{13}{|c|}{$\begin{array}{l}\text { Women at the age of } \\
\text { diagnosis/selection } \\
\geq 54 \text { years }\end{array}$} \\
\hline $\mathrm{CC}$ & - & - & & & 4 & 4 & & & - & - & & \\
\hline $\mathrm{CT}$ & 1 & 2 & & & 1 & 3 & & & - & - & & \\
\hline $\mathrm{TT}$ & 2 & 1 & & & - & - & & & - & - & & \\
\hline
\end{tabular}

MTHFR 677TT/1298CC genotype was not observed in the study population

$O R$ odds ratio, $C I$ confidence interval

${ }^{\text {a }}$ We used 54 years old as an arbitary criterio corresponding to the median age at diagnosis/selection of GC cases 
Table 5 Distribution of MTHFR genotypes in overall GC-relative cases and in GC-relative cases stratified by sex

\begin{tabular}{|c|c|c|c|c|c|c|c|c|c|c|c|c|}
\hline \multirow[t]{2}{*}{ MTHFR 677} & \multicolumn{4}{|l|}{ AA } & \multicolumn{4}{|c|}{ MTHFR 1298 AC } & \multicolumn{4}{|l|}{$\mathrm{CC}$} \\
\hline & Cases $(n)$ & Controls $(n)$ & OR & $95 \% \mathrm{CI}$ & Cases $(n)$ & Controls $(n)$ & OR & $95 \% \mathrm{CI}$ & Cases $(n)$ & Controls $(n)$ & OR & $95 \% \mathrm{CI}$ \\
\hline \multicolumn{13}{|l|}{ GC-relatives } \\
\hline $\mathrm{CC}$ & 1 & 24 & 1.0 & - & 11 & 90 & 0.2 & $(0.1-0.9)$ & 2 & 38 & 0.4 & $(0.1-2.0)$ \\
\hline $\mathrm{CT}$ & 3 & 98 & 0.7 & $(0.1-7.4)$ & 15 & 137 & 0.9 & $(0.4-2.0)$ & - & 3 & & \\
\hline $\mathrm{TT}$ & 5 & 57 & 2.1 & $(0.2-18.9)$ & - & 7 & & & - & - & & \\
\hline \multicolumn{13}{|l|}{ Men } \\
\hline $\mathrm{CC}$ & 0 & 19 & 1.0 & - & 7 & 58 & 5.0 & $(0.3-91)$ & 1 & 23 & 2.5 & $(0.1-65)$ \\
\hline $\mathrm{CT}$ & 1 & 70 & 0.8 & $(0.0-21)$ & 10 & 95 & 4.3 & $(0.0-76)$ & - & 1 & & \\
\hline $\mathrm{TT}$ & 2 & 44 & 2.2 & $(0.1-48)$ & - & 5 & & & & & & \\
\hline \multicolumn{13}{|l|}{ Women } \\
\hline $\mathrm{CC}$ & 1 & 5 & 1.0 & - & 4 & 32 & 0.6 & $(0.1-6.2)$ & 1 & 15 & 0.3 & $(0.2-6.4)$ \\
\hline CT & 2 & 28 & 0.4 & $(0.1-4.7)$ & 5 & 42 & 0.5 & $(0.6-6.2)$ & - & 2 & & \\
\hline TT & 3 & 13 & 1.1 & $(0.1-14)$ & - & 2 & & & - & - & & \\
\hline
\end{tabular}

MTHFR 677TT/1298CC genotype was not observed in the study population

$O R$ odds ratio, $C I$ confidence interval

confirmed when age-sex-matched GC and control groups were compared $(\mathrm{OR}=2.3714 ; 95 \% \mathrm{CI}$ : 0.9992 to 5.6283$)$. Any $1298 \mathrm{CC}$ genotype correlation was found in GC when compared with controls (Tables 2 and 3). We found that only the 677TT genotype increased the risk for GC, while the single 677 T allele was statistically insignificant (Tables 2 and 3). This is in accordance with a recessive mode of inheritance for a GC risk due to the mutation.

$677 \mathrm{TT}$ and $1298 \mathrm{CC}$ frequencies in our control series (13-14\% and 9-14\%) were similar to those found in other studies in Europe (5-30\% and 10\%, respectively) [19,40] and in Italy (14-19.9\% and 7.5\%) [41]. The crude 677TT OR found, 1.98 and 2.37, was in accordance with that found in the majority of Italian studies, 1.81 to 2.95 $[18,19]$, but differed from Vollset study, 0.90 [15]. Nevertheless, the 677TT and 1298CC frequencies reported (21.3\% and $7.7 \%$, respectively) were not dissimilar to ours (13-14\% and 9-14\%) [15]. Nonetheless, although data of MTHFR genotyping based on stratification by sex and age did not reach statistical significance in our series (Table 4),
Fig. 2 MTHFR polymorphisms and $H$. pylori infection in GC patients and in GC-first grade relatives. a The table indicates the number of persons (columns 2 and 4 ) with a confirmed histological HP infection in association with the 677 and 1298 genotypes. b The graphic evidences the similar HP infection frequency in GC and in GC-relatives series. No preferential HP distribution was found among the 677 genotypes
A)

\begin{tabular}{|c|c|c|c|c|c|c|c|c|c|c|c|c|c|c|c|c|}
\hline \multirow[b]{3}{*}{ GC } & \multicolumn{4}{|c|}{$\begin{array}{c}667 \\
\text { genotype }\end{array}$} & \multicolumn{4}{|c|}{$\begin{array}{c}667 \\
\text { genotype/Hp pos }\end{array}$} & \multicolumn{4}{|c|}{$\begin{array}{c}1298 \\
\text { genotype }\end{array}$} & \multicolumn{4}{|c|}{$\begin{array}{c}1298 \\
\text { genotype/Hp pos }\end{array}$} \\
\hline & $\mathrm{CC}$ & CT & TT & $n$ & $\overline{\mathrm{CC}}$ & CT & TT & tot & $\mathbf{A A}$ & $\overline{\mathrm{AC}}$ & $\mathrm{CC}$ & $n$ & $\mathbf{A A}$ & $\overline{\mathbf{A C}}$ & $\overline{\mathrm{CC}}$ & tot \\
\hline & 8 & 6 & & 17 & 4 & & 1 & 8 & 6 & 9 & 2 & 17 & 2 & 5 & 1 & 8 \\
\hline GC-relatives & 14 & 18 & 5 & 37 & 7 & 11 & 2 & 20 & 9 & 26 & 2 & 37 & 4 & 14 & 2 & 20 \\
\hline
\end{tabular}

B)

HP infection frequencies in GC and GC-relatives

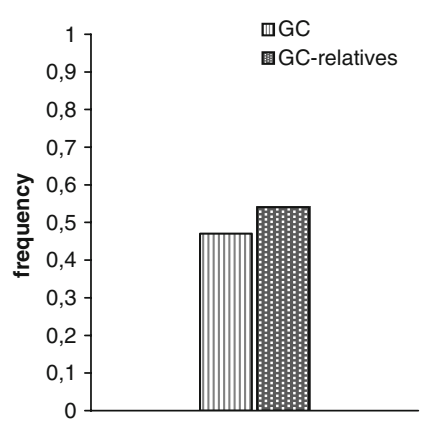

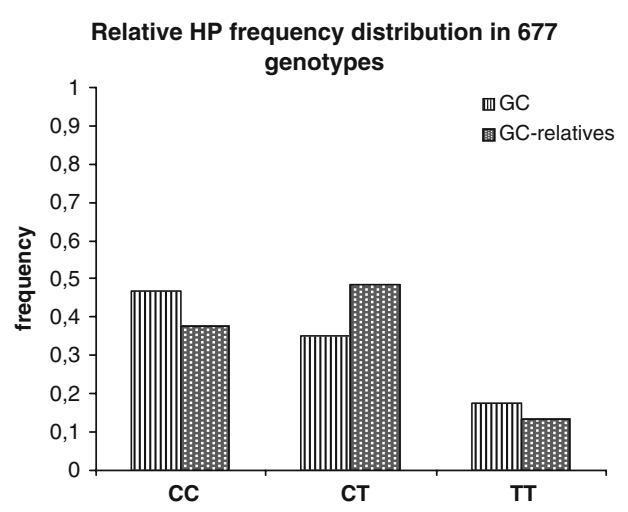


data are suggestive that the difference in MTHFR polymorphism association and GC risk may be partially ascribed to sex and age of recruited cases. An association of homozygous 677TT genotype in women group and the decrease of wild-type 677 allele frequency in both the sex (Tables 2 and 3) support this finding. The suggestion, as evidenced in Table 4, that an association could exist between the presence of both the MTHFR, 677, and 1298 variant genotypes, and a higher risk of GC in patients $\geq 54$ at diagnosis/recruitment, and the possible $1298 \mathrm{CC}$ reduced risk in women, as found also in other cancer [42], require further studies on a large series to be definitely elucidate.

Thus, the reasons for discrepancy between our and other authors' data and those reported [15] remain unknown, but the increased frequency of the 1298CC genotype in their GC cases could exclude an increase of 677TT. In fact, although the two 677TT and 1298CC polymorphic sites were in linkage disequilibrium [43,44], the 677TT/1298CC genotype was absent in our series, as well as in others [15], suggesting that $677 \mathrm{TT} / 1298 \mathrm{CC}$ genotype results in a severely adverse phenotype. Moreover, the limited number of cases studied, the geographical divergences (the study summarizes Italy, Spain, and Greece cases [15]), and the unknown geneticenvironmental interactions could also be implicated.

Anyway, all studies concerning Italian patients attested at least one MTHFR genotype with a known reduced folate reductase activity (677TT or 1298CC), [28] associated with GC.

Based on this finding, we analyzed the MTHFR polymorphisms in a series of GC-relatives individuals with the aim to improve techniques in the identification of high-risk subpopulations (i.e., genetic counseling).

Despite the restriction of the limited number of subjects enrolled ( $n=37)$, our data evidenced an increase in MTHFR 677TT genotype only in ascertained GC cases, but not on GC-relatives (13.5\% vs controls $14.1 \%$, Tables 2 and 3). Also, the difference in $1298 \mathrm{CC}$ genotype frequencies among the GC-relatives (5.7\%), GC (8.8\%) and controls (14.1\%) was statistically insignificant. Only an increase in 1298 heterozygosis was found in GC-relatives (70.3\%) with respect to $\mathrm{GC}(47.4 \%, \mathrm{OR}=2.22,95 \% \mathrm{CI}: 1.072$ to 4.605$)$.

In conclusion, our data reinforce the role of 677TT in GC development in the northeast of Italy, but our results are not as consistent as to lead to a sanitary benefit for a MTHFR genetic consultation among GC-relatives. In addition, in our study, prevalence of $H$. pylori infection in GC-relatives was similar to that in GC and resulted with a distribution independent of 677 genotypes (Figs. 1 and 2). Thus, the identification of 677TT genotype that is colonized by $H$. pylori does not to constitute a subset of subjects that may benefit more than others from $H$. pylori eradication (since this treatment could result in reduced GC risk).
Acknowledgments The authors wish to thank Dr. Luigino Dal Maso for statistical analysis consultation, Mrs. Anna Vallerugo for her contribution to this study, and Programma Integrato Oncologia, Tematica 2: "Diagnostica Molecolare Avanzata" for the financial support.

Open Access This article is distributed under the terms of the Creative Commons Attribution Noncommercial License which permits any noncommercial use, distribution, and reproduction in any medium, provided the original author(s) and source are credited.

\section{References}

1. Leon DA, Smith GD. Infant mortality, stomach cancer, stroke, and coronary heart disease: ecological analysis. BMJ. 2000;320: 1705-6.

2. Parkin DM, Bray F, Ferlay J, Pisani P. Global cancer statistics 2002. CA Cancer J Clin. 2005;55:74-108.

3. AIRT Working Group: I tumori in Italia-rapporto 2006. Incidence and mortality data of the cancer registries, 1998-2002.

4. Hundahl SA, Phillips JL, Menck HR: The National Cancer Data Base Report on poor survival of U.S. gastric carcinoma patients treated with gastrectomy: Fifth Edition American Joint Committee on Cancer staging, proximal disease, and the "different disease" hypothesis. Cancer. 2000;88:921-32.

5. Munoz N, Franceschi S. Epidemiology of gastric cancer and perspectives for prevention. Salud Publica Mex. 1997;39:318-30.

6. Barber M, Fitzgerald RC, Caldas C. Familial gastric canceraetiology and pathogenesis. Best Pract Res Clin Gastroenterol. 2006;20:721-34.

7. Carneiro F, Oliveira C, Suriano G, Seruca R. Molecular pathology of familial gastric cancer, with an emphasis on hereditary diffuse gastric cancer. J Clin Pathol. 2008;61:25-30.

8. Dhillon PK, Farrow DC, Vaughan TL, et al. Family history of cancer and risk of esophageal and gastric cancers in the United States. Int J Cancer. 2001;93:148-52.

9. Malaty HM, Engstrand L, Pedersen NL, Graham DY. Helicobacter pylori infection: genetic and environmental influences. A study of twins. Ann Intern Med. 1994;120:982-6.

10. Foschi R, Lucenteforte E, Bosetti C, et al. Family history of cancer and stomach cancer risk. Int J Cancer. 2008;123:1429-32.

11. Brenner $\mathrm{H}$, Bode $\mathrm{G}$, Boeing $\mathrm{H}$. Helicobacter pylori infection among offspring of patients with stomach cancer. Gastroenterology. 2000;118:31-5.

12. Brenner H, Rothenbacher D, Arndt V. Epidemiology of stomach cancer. Methods Mol Biol. 2009;472:467-77.

13. Leung WK, $\mathrm{Ng}$ EK, Lam CC, et al. Helicobacter pylori infection in 1st degree relatives of Chinese gastric cancer patients. Scand J Gastroenterol. 2006;41:274-9.

14. Chang YW, Han YS, Lee DK, et al. Role of Helicobacter pylori infection among offspring or siblings of gastric cancer patients. Int J Cancer. 2002;101:469-74.

15. Vollset SE, Igland J, Jenab M, et al. The association of gastric cancer risk with plasma folate, cobalamin, and methylenetetrahydrofolate reductase polymorphisms in the European Prospective Investigation into Cancer and Nutrition. Cancer Epidemiol Biomarkers Prev. 2007;16:2416-24.

16. Zintzaras E. Association of methylenetetrahydrofolate reductase (MTHFR) polymorphisms with genetic susceptibility to gastric cancer: a meta-analysis. J Hum Genet. 2006;51:618-24.

17. Sun L, Sun YH, Wang B, Cao HY, Yu C. Methylenetetrahydrofolate reductase polymorphisms and susceptibility to gastric cancer in Chinese populations: a meta-analysis. Eur J Cancer Prev. 2008;17:446-52. 
18. Larsson SC, Giovannucci E, Wolk A. Folate intake, MTHFR polymorphisms, and risk of esophageal, gastric, and pancreatic cancer: a meta-analysis. Gastroenterology. 2006;131:1271-83.

19. Boccia S, Hung R, Ricciardi G, et al. Meta- and pooled analyses of the methylenetetrahydrofolate reductase C677T and A1298C polymorphisms and gastric cancer risk: a HuGE-GSEC review. Am J Epidemiol. 2008;167:505-16.

20. Blount BC, Mack MM, Wehr CM, et al. Folate deficiency causes uracil misincorporation into human DNA and chromosome breakage: implications for cancer and neuronal damage. Proc Natl Acad Sci U S A. 1997;94:3290-5.

21. Kim YI. Folate and carcinogenesis: evidence, mechanisms, and implications. J Nutr Biochem. 1999;10:66-88.

22. Wainfan E, Poirier LA. Methyl groups in carcinogenesis: effects on DNA methylation and gene expression. Cancer Res. 1992; 52:2071s-7.

23. Sanjoaquin MA, Allen N, Couto E, Roddam AW, Key TJ. Folic acid intake and colorectal cancer risk: a meta-analytical approach. Int J Cancer. 2005;113:825-8.

24. Shrubsole MJ, Gao YT, Cai Q, et al. MTHFR polymorphisms, dietary folate intake, and breast cancer risk: results from the Shanghai Breast Cancer Study. Cancer Epidemiol Biomarkers Prev. 2004;13:190-6.

25. Kobayashi M, Tsubono Y, Sasazuki S, Sasaki S, Tsugane S. Vegetables, fruit and risk of gastric cancer in Japan: a 10-year follow-up of the JPHC Study Cohort I. Int J Cancer. 2002;102:39-44.

26. Larsson SC, Bergkvist L, Wolk A. Fruit and vegetable consumption and incidence of gastric cancer: a prospective study. Cancer Epidemiol Biomarkers Prev. 2006;15:1998-2001.

27. Kelley JR, Duggan JM. Gastric cancer epidemiology and risk factors. J Clin Epidemiol. 2003;56:1-9.

28. de Bree A, Verschuren WM, Bjørke-Monsen AL, van der Put NM, Heil SG, Trijbels FJ, et al. Effect of the methylenetetrahydrofolate reductase $677 \mathrm{C}->\mathrm{T}$ mutation on the relations among folate intake and plasma folate and homocysteine concentrations in a general population sample. Am J Clin Nutr. 2003;77:687-93.

29. Xiao SD, Meng XJ, Shi Y, Hu YB, Zhu SS, Wang CW. Interventional study of high dose folic acid in gastric carcinogenesis in beagles. Gut. 2002;50:61-4.

30. Bland JM, Altman DG. Statistics notes. The odds ratio. BMJ. 2000;320:1468.

31. Weir DG, McGing PG, Scott JM. Folate metabolism, the enterohepatic circulation and alcohol. Biochem Pharmacol. 1985;34:1-7.
32. McMartin KE, Collins TD, Eisenga BH, Fortney T, Bates WR, Bairnsfather L. Effects of chronic ethanol and diet treatment on urinary folate excretion and development of folate deficiency in the rat. J Nutr. 1989;119:1490-7.

33. Yi-Chia Lee, Jyh-Ming Liou, Chun-Ying Wu, Jaw-Town LinL. Eradication of Helicobacter pylori to prevent gastroduodenal diseases: hitting more than one bird with the same stone. Therapeutic Advances in Gastroenterology. 2008;1:111-20.

34. Suzuki T, Matsuo K, Hirose K, et al. One-carbon metabolismrelated gene polymorphisms and risk of breast cancer. Carcinogenesis. 2008;29:356-62.

35. Ryan-Harshman M, Aldoori W. Diet and colorectal cancer: review of the evidence. Can Fam Physician. 2007;53:1913-20.

36. Fallon UB. Commentary: colon cancer, folate and genetic status. Int J Epidemiol. 2003;32:67-70.

37. Shi Q, Zhang Z, Li G, Pillow PC, Hernandez LM, Spitz MR, et al. Sex differences in risk of lung cancer associated with methylenetetrahydrofolate reductase polymorphisms. Cancer Epidemiol Biomarkers Prev. 2005;14:1477-84.

38. Graziano F, Kawakami K, Ruzzo A, et al. Methylenetetrahydrofolate reductase $677 \mathrm{C} / \mathrm{T}$ gene polymorphism, gastric cancer susceptibility and genomic DNA hypomethylation in an at-risk Italian population. Int J Cancer. 2006;118:628-32.

39. Lissowska J, Gail MH, Pee D, Groves FD, Sobin LH, et al. Diet and stomach cancer risk in Warsaw, Poland. Nutr Cancer. 2004;48:149-59.

40. Ueland PM, Hustad S, Schneede J, Refsum H, Vollset SE. Biological and clinical implications of the MTHFR C677T polymorphism. Trends Pharmacol Sci. 2001;22:195-201.

41. Macis D, Maisonneuve P, Johansson H, et al. Methylenetetrahydrofolate reductase (MTHFR) and breast cancer risk: a nestedcase-control study and a pooled meta-analysis. Breast Cancer Res Treat. 2007;106:263-71.

42. Curtin K, Bigler J, Slattery ML, Caan B, Potter JD, Ulrich CM. MTHFR C677T and A1298C polymorphisms: diet, estrogen, and risk of colon cancer. Cancer Epidemiol Biomarkers Prev. 2004;13:285-92.

43. Ogino S, Wilson RB. Genotype and haplotype distributions of MTHFR677C $>$ T and 1298A $>$ C single nucleotide polymorphisms: a meta-analysis. J Hum Genet. 2003;48:1-7.

44. Ulvik A, Ueland PM, Fredriksen A, et al. Functional inference of the methylenetetrahydrofolate reductase $677 \mathrm{C}>\mathrm{T}$ and $1298 \mathrm{~A}>\mathrm{C}$ polymorphisms from a large-scale epidemiological study. Hum Genet. 2007;121:57-64. 